\title{
Effect of Climate on the Distribution of Fusarium spp. Causing Crown Rot of Wheat in the Pacific Northwest of the United States
}

\author{
Grant J. Poole, Richard W. Smiley, Carl Walker, David Huggins, Richard Rupp, John Abatzoglou, \\ Kimberly Garland-Campbell, and Timothy C. Paulitz
}

First, third, and fifth authors: Department of Crop and Soil Sciences, Washington State University, P.O. Box 6420, Pullman 99164-6420; second author: Columbia Basin Agricultural Research Center, Oregon State University, P.O. Box 370, Pendleton 97801; fourth author: United States Department of Agriculture-Agricultural Research Service (USDA-ARS) Land Management and Water Conservation Research Unit, Department of Crop and Soil Sciences, Washington State University; sixth author: Department of Geography, University of Idaho, P.O. Box 443021, Moscow 83844-3021; seventh author: USDA-ARS Wheat Genetics, Quality, Physiology and Disease Research Unit, Department of Crop and Soil Sciences, Washington State University; and eighth author: USDA-ARS, Root Disease Unit and Biological Control Research Unit, Department of Plant Pathology, Washington State University.

Accepted for publication 15 May 2013.

\section{ABSTRACT}

Poole, G. J., Smiley, R. W., Walker, C., Huggins, D., Rupp, R., Abatzoglou, J., Garland-Campbell, K., and Paulitz, T. C. 2013. Effect of climate on the distribution of Fusarium spp. causing crown rot of wheat in the Pacific Northwest of the United States. Phytopathology 103:11301140

Fusarium crown rot (FCR) is one of the most widespread root and crown diseases of wheat in the Pacific Northwest (PNW) of the United States. Our objectives were to characterize crown rot severity and distribution throughout the PNW by conducting a survey of 210 fields covering the diverse dryland wheat-producing areas of Washington and Oregon and to utilize a factor analysis statistical approach to determine the effects of climate and geography on species distribution and disease severity. Climatic variables were based on 30-year averages and 2008 and 2009 separately (the 2 years of the survey). Mean annual temperature, mean temperature in the coldest month, mean temperature in the warmest month, mean annual precipitation, snowfall, elevation, soil type, and cropping intensity were highly intercorrelated. The factor analysis of the climate variables resulted in the development of two latent factors that could be used as predictor variables in logistic regression models for the

Fusarium crown rot (FCR) is a major yield-limiting disease of dryland wheat (Triticum aestivum L.) and barley (Hordeum vulgare L.). Crop yields are reduced due to rotting seed, seedlings, roots, crowns, and basal stems resulting in seedling mortality, premature lodging, and impaired grain filling $(30,36,43)$. In the Pacific Northwest (PNW) region of the United States, the disease causes average annual yield losses of $9.5 \%$ at a value of as much as US\$69 million, based on 2007 production figures (41). The presence of FCR decreased yield in 13 commercial fields in the PNW by as much as $35 \%$; yields were decreased by up to $61 \%$ under inoculated experimental conditions (41).

The disease is caused by a complex of species of which $\mathrm{Fu}$ sarium pseudograminearum (O'Donnell \& T. Aoki) (=F. graminearum group I, =Gibberella coronicola) and F. culmorum (W. G. Sm.) Sacc.) are the most significant $(8,27,42)$. Infection results in chocolate to reddish-brown symptoms on roots or shoot

Corresponding author: T. C. Paulitz; E-mail address: paulitz@wsu.edu

http://dx.doi.org/10.1094/PHYTO-07-12-0181-R

This article is in the public domain and not copyrightable. It may be freely reprinted with customary crediting of the source. The American Phytopathological Society, 2013 presence or absence of Fusarium spp. and of FCR disease scores. Isolates of Fusarium spp. were recovered from $99 \%$ of 105 fields sampled in 2008 and $97 \%$ of fields in 2009. There were differences between years for responses of FCR and nodes scores, and isolations of Fusarium pseudograminearum with more significant results in 2008, due to warmer drier weather. Results of the factor analysis showed that the distribution of F. pseudograminearum occurred in a greater frequency in areas of the PNW at lower elevations with lower moisture and higher temperatures in 2008, whereas $F$. culmorum occurred in greater frequency in areas at higher elevations with moderate to high moisture and cooler temperatures consistently across both years. Disease scores increased with increasing levels of factors 1 (primarily temperature) and 2 (primarily precipitation). Both the frequency of pathogen species and disease scores were influenced by the year, indicating that soilborne pathogens are responsive to short-term changes in environment. This factor analysis approach can be utilized in studies to determine the effects of climate and other environmental (soil, cropping system, and so on) factors on the distribution and severity of root diseases.

Additional keywords: Fusarium culmorum. internodes $(4,13)$. Lesions extending to the fourth or fifth node can be accompanied by salmon-colored sporodochia, which are masses of macroconidia. The infection of the crown (lower stem) region constricts the vascular system and limits water transport capacity $(8,40)$. Subsequent drought stress experienced in the later stages of wheat crop growth results in formation of whiteheads containing little to no seed $(8,10)$. Whiteheads are often used as an indicator of FCR injury to quantify the amount of disease present but this method can be misleading because aboveground symptoms are not always obvious $(8,41)$. Whiteheads can be also caused by other root-rotting pathogens $(20,43)$.

The earliest documentation of FCR in the PNW was reported by Cook (12). Using the nomenclature of the time, more than $90 \%$ of the isolates from diseased fields were $F$. roseum f. sp. cerealis 'Culmorum' and F. roseum $\mathrm{f}$. sp. cerealis 'Graminearum', with Culmorum being predominantly present. F. roseum f. sp. cerealis 'Avenaceum' was isolated occasionally from those samples. A more recent survey of the wheat-growing areas of eastern Oregon and southern Washington documented the occurrence of $F$. pseudograminearum more often than $F$. culmorum in crops with crown rot in nine counties, while the opposite was true in three counties $(12,43)$. F. culmorum was the primary causal agent of FCR in southeastern Idaho, dominated by higher eleva- 
tions (46). Root-rot-causing organisms in Montana were identified as Bipolaris sorokiniana (15\%), F. culmorum (13\%), and F. pseudograminearum (8\%) (25).

Surveys of root-rot-causing organisms in dryland wheat have been conducted throughout the world $(2,5,7,10,12,17,25,35$, $43,45,46)$. Although the causal agents of FCR are most frequently a complex of $F$. pseudograminearum and $F$. culmorum, other pathogens capable of causing crown infection include $F$. avenaceum (Fr.) Sacc. $(=G$. avenacea) and Microdochium nivale (Fr.) Samuels \& I. C. Hallett (=Monographella nivalis) (41). It is widely accepted that $F$. pseudograminearum is the dominant species responsible for causing crown rot in arid zones of the PNW and Australia $(3,10,11,42,43)$.

Several other genera also cause root rots of cereal grains, including the causal agent of common root rot, Bipolaris sorokiniana (Sacc.) Shoemaker (=Cochliobolus sativus) (12,14,25, 27,32); the causal agent of take-all, Gaeumannomyces graminis (Sacc.) Arx \& D. L. Olivier and G. graminis var. tritici J. Walker; Rhizoctonia spp. (Rhizoctonia solani Kühn and R. oryzae Ryker \& Gooch); and Pythium Pringsh. spp. $(38,43,45)$. In the PNW, the last three tend to be more prevalent in spring wheat cropping systems (38). Eyespot (caused by Oculimacula acuformis (Boerma, R. Pieters \& Hamers) Crous \& W. Gams and $O$. yallundae (Wallwork \& Spooner) Crous \& W. Gams) is also a major yield-limiting factor in winter wheat where precipitation is high (22).

Winter wheat is the predominant crop in much of the dryland region of the PNW (also referred to as the Inland Northwest or the Columbia Basin) but the environment is quite diverse within these $\approx 160,000 \mathrm{~km}^{2}$. Mean annual temperature (MAT) ranges from 6 to $12.5^{\circ} \mathrm{C}$, annual precipitation in the region ranges from $<125$ to $>600 \mathrm{~mm}$, and elevation rises from sea level to $>1,500 \mathrm{~m}$. Most annual precipitation occurs from October through March, with only 5 to $10 \%$ occurring from July through September (37). These climate differences and geological history combined to create great diversity in soil types (several thousand soil series are identified and mapped in Washington state alone) (18). Soil depths range from $<1$ to $>7 \mathrm{~m}$ (18). In the Columbia Basin, sandy silt loams predominate in the southwest, with clay slit loams in the northeastern part of the region. Due to soil and climate variability, dryland cropping systems in the region range from a 3 -year rotation of winter wheat, spring cereal, and spring legume to a 2-year rotation of winter wheat and fallow and are planted under conventional or conservation tillage systems (37). These differentiating factors of growing degree days, annual precipitation, and soil depth were used to delineate six agronomic zones of the PNW, which could be used as a geographical base for extrapolating research results for the PNW $(15,16)$.

Complex interactions among climate, cropping systems, and tillage also influence the distribution of Fusarium spp. as well as disease severity $(3,25,39,40,43)$. F . pseudograminearum has been found more frequently in low precipitation zones $(250$ to $500 \mathrm{~mm}$ ) while $F$. culmorum occurred in zones with higher precipitation (>500 mm) (2). In the PNW, the incidence of FCR was the greatest in seasons with low precipitation (41). A moderate but significant negative correlation was reported for the occurrence of $F$. pseudograminearum with precipitation and elevation; however, the six PNW agronomic zones did not explain the occurrence or frequency of FCR pathogens (43). Strausbaugh et al. (46) reported that $F$. culmorum dominated in the cooler, higher elevations surveyed in Idaho. Soil type and winter- versus spring-habit wheat also influenced species distribution (25). Tillage has also been shown to influence Fusarium spp. presence and quantity as well as distribution within a field $(6,29,47)$. Backhouse and Burgess (3) reported significant associations between climate and Fusarium spp. distribution in Australia. FCR is well known for a high degree of variation between host cultivars and years due to the nature of the infection mechanism and influence of climate on species distribution and disease severity $(41,43,44)$. Smiley et al. (44) described the highly variable nature of FCR across experimental locations and years from data with experiments conducted utilizing $>16$ cultivars over 8 years at several locations.

Although previous surveys of the presence of Fusarium spp. associated with the crown rot disease have been conducted in eastern Oregon and southern Washington (41), an extensive area of Washington comprising the Columbia Basin and areas north was not surveyed. Crown rot disease is prevalent in this region, where most of the dryland winter wheat of the PNW is produced. The objectives of this work were to (i) determine the occurrence of FCR and Fusarium spp. distributions covering the broad geographic region comprising the major wheat-producing areas of Washington and Oregon and (ii) determine which climate, cropping system, and geographical factors most influence species distribution and FCR disease in this region.

\section{MATERIALS AND METHODS}

Sampling of field sites. Field locations were selected randomly and sampled systematically over a broad geographic area covering the dryland wheat region from 14 Washington counties, four Oregon counties, and one location in northern Idaho. Survey sites included 210 randomly selected commercial wheat fields, including 21 Washington State University Cooperative Extension Cereal Variety Testing sites for winter wheat. The survey was conducted during summer 2008 and 2009.

Samples were taken from winter wheat stubble shortly after harvest. Sampling began near Pendleton, OR on 7 July 2008 and 10 July 2009. Sampling followed the harvest pattern throughout the region until 15 September 2008 and 25 September 2009, finishing near Pullman and near Spokane in eastern Washington, respectively. The sampling distance between fields was 17 to 80 $\mathrm{km}$. Sampling density was greater where FCR had previously been reported in Oregon and north-central Washington and in areas that had not been sampled previously. All fields sampled were geo-referenced using a Magellan global positioning system (GPS) meter (Triton model; Magellan Mfg., San Dimas, CA) at each 1-m row subsample in 2008 (see below) but only at each field in 2009. Fields sampled in 2009 were from winter wheat stubble in the closest proximity of those sampled in 2008, within $3.2 \mathrm{~km}$.

Five subsamples were taken from each field. A subsample was defined as a 1-m row of wheat stubble and roots dug to a depth of $10 \mathrm{~cm}$ below the crown. A single subsample was obtained after walking $100 \mathrm{~m}$ into a field from the edge, and four additional subsamples were taken from that point by walking $25 \mathrm{~m}$ between each sample in a zigzag pattern. Each subsample was placed in a labeled paper bag and dried at ambient temperatures prior to scoring.

FCR disease scores. At the time of scoring, 10 stems were randomly chosen from plants within the subsample excised from the dug-up crowns at the base of the stem. Each stem was scored for FCR disease severity based on a 0 to 10 scale, where $0=$ no disease; 1 to $2=$ minor symptoms on crown within the first internode region; 3 to $4=$ obvious symptoms on crown within the first internode region; 5 to $6=$ pronounced symptoms on the crown, with obvious darkened plant tissue due to infection penetrating to the third leaf; 8 to $9=$ advanced darkened symptoms; and $10=$ severe darkened symptoms throughout tissues (as modified from Nicol et al. [27]). The number of internodes (node score) with disease symptoms was also recorded for each stem. In total, 5,100 stems were selected and scored each year (2008 and 2009), with 10,200 stems rated in all.

Species isolation, culture, and identification. A stem was randomly selected from each subsample, with five stem samples per field (500 isolates total per year). The stems that were selected tended to be symptomatic. A $2-\mathrm{cm}$ section was cut from each 
stem, surface disinfested in $0.05 \% \mathrm{NaOCl}$ for $30 \mathrm{~s}$ followed by a 6-min rinse in double-distilled water, and placed on Synthetischer Nährstoffärmer agar (SNA) (28) (1 g of $\mathrm{KH}_{2} \mathrm{PO}_{4}, 1 \mathrm{~g}$ of $\mathrm{KNO}_{3}$, $0.5 \mathrm{~g}$ of $\mathrm{MgSO}_{4} \cdot 7 \mathrm{H}_{2} \mathrm{O}, 0.5 \mathrm{~g}$ of $\mathrm{KCl}, 0.2 \mathrm{~g}$ of glucose, $0.2 \mathrm{~g}$ of saccharose, and $20 \mathrm{~g}$ of agar per 1 liter of media). Cultures were placed at room temperature in natural light for 3 days.

After 3 days, $1-\mathrm{cm}^{2}$ pieces were cut from the SNA and fungal growth surrounding each cut stem piece was transferred to a fresh SNA plate. Plates were incubated for 3 weeks in the dark. Fungal species present were identified for each subsample from each field on the basis of morphological characters of macroconidia observed through a light microscope at $\times 40$ and $\times 100(9,21,26)$.

Single-spore cultures were made for each field. Each SNA plate was viewed under the dissecting scope and a $1-\mathrm{cm}$ piece of agar containing sporodochia was cut out and placed in $1 \mathrm{ml}$ of water in a 5-ml tube. The tube was vortexed for $5 \mathrm{~s}$ and $90 \mu \mathrm{l}$ was pipetted onto a half-strength potato dextrose agar plate containing chloramphenicol. Plates were incubated for $24 \mathrm{~h}$ at $22^{\circ} \mathrm{C}$. Species presence was scored as 1 (present) or 0 (absent) for each species identified from each subsample. For the archived collection, monospore isolations were made by viewing these plates under the dissecting microscope, then excising and transferring single germinated spores to new SNA plates.

Climate, crop, and geographic data. Elevation was obtained for each sample location from the Digital Elevation Model included in the climate databases. Climate data were downloaded from the database developed by the United States Department of Agriculture (USDA) Forest Service Moscow Forestry Sciences Laboratory (http://forest.moscowfsl.wsu.edu/climate/). These data include 21 variables for 30-year norms for the period 1961 to 1990. Data were obtained as in Rehfeldt (34) for each of the GPS coordinates from which samples were taken. The variables were derived from monthly climate surfaces using Hutchinson's thinplate splines and were selected based on their predictive importance in biology (34). A correlation analysis of these 21 variables indicated that most were highly correlated. As a result, a subset including MAT, mean annual precipitation (MAP), mean temperature in the coldest month (MTCM), mean temperature in the warmest month (MTWM), and snowfall (SNOW) were the only variables kept for the analyses described below. Data obtained were based on 30-year averages as well as within-season variables for each GPS location in 2008 and 2009. We modeled daily snowfall liquid equivalents using concomitant daily mean temperature and accumulated precipitation obtained by extracting data from co-located 4-km raster data from the daily surface meteorological data set of Abatzoglou (1). The percent precipitation that fell as snow on any day was estimated using an empirical transformation based on temperature derived from worldwide temperature-precipitation phase relationships from land-based stations. Soil data for each of the sample locations based on GPS coordinates were obtained from the USDA Natural Resources Conservation Service Web Soil Survey (http:// websoilsurvey.sc.egov.usda.gov/App/Hopepage.htm). Soil textures were coded as one of three classification categories: sandy-loam, loam, or silty-loam. The categories cover a range of values for percent sand, silt, or clay. We chose the center point of each category to define percent sand, silt, or clay for each field that was sampled. For the centers of these three categories, the amounts of sand and silt were almost perfectly negatively correlated. Therefore, we chose the percent sand content as a replacement variable for the original categorical soil texture variable. Cropping intensities in survey locations were recorded by examining the pixel intensity of data layers on ArcGIS models. This raster set was produced by R. Rupp by using the National Agricultural Statistic Service Crop Layer product, derived from satellite imagery in 2007. These data were used as an indicator for cropping system because a 3 -year rotation with annual cropping would have a higher cropping intensity than the 2-year wheat-fallow rotation.
For example, annual cropping systems would have a value of $100 \%$, whereas areas cropped every other year, such as the wheat-summer fallow areas, would have a value of $50 \%$. The final data set for the climate and geographic variables included elevation, MAT, MAP, MTCM, MTWM, SNOW, cropping intensity, and percent sand.

Statistical methods. Factor analysis. Pearson correlations were calculated to estimate relatedness among the 30-year averaged continuous climate and geographic variables. Correlations were calculated between elevation, MAT, MAP, MTCM, MTWM, SNOW, cropping intensity, and percent sand content. The highly correlated climate variables complicated our efforts to perform regression analysis of the effects of climate, soil type, and cropping system on disease scores and species presence. Therefore, factor analysis was used to reduce the 30-year interrelated variables into compact latent factors based on the climate, crop, and geographic variables for ease of interpretation and to increase the strength and resolution of the analysis. Only variables which had correlation coefficients of $>0.5$ with at least one other variable were included in the factor analysis; therefore, sand content and cropping system were not included. Prior to conducting factor analysis, locations with supplemental irrigation were excluded. All data analyses were conducted using SAS software (version 9.3; SAS Institute Inc., Cary, NC). Graphs were generated in SAS and using code written in R (33).

Factor analysis was conducted using the FACTOR and SCORE procedures with the common factor method in SAS to estimate latent factor values for each field sampled for two rotated factors. Analysis was limited to two factors because only the first two eigenvalues of the correlation matrix were $>1$ (the KaiserGuttman rule) (23) and the scree plot of eigenvalue by the number of factors with a near linear trend starting at 3 (23). The initial factor solution was rotated to improve interpretation using a varimax rotation. This rotation was chosen because it yields orthogonal latent factors, and the primary goal of our factor analysis was to avoid multicollinearity in the linear modeling that followed.

Logistic regression analysis of Fusarium spp. presence. The binary trait presence or absence of $F$. culmorum and F. pseudograminearum from five subsamples from each field was related to climate and geographic variables and year effects using logistic regression with a logit link in the LOGISTIC procedure in SAS. The model included the two estimated latent factors plus sand content and cropping system, which were not included in the factor analysis, and their interactions as fixed effects. Separate analyses were conducted for each species and each year, due to significant interactions of treatment effects with year. In order to further explore the differences between 2008 and 2009, individual climate variables for each of those years (within growing season) were used in logistic regression models for the species presence or absence for that year. Thus, for 2008, the 2008 MAT, MAP, MTWM, MTCM, and SNOW were used as predictor variables for the presence of $F$. culmorum or $F$. pseudograminearum obtained from fields sampled in 2008. The same analysis was repeated for 2009.

Logistic analysis of disease scores. The disease scores, crown score, and node score were scored as ordinal variables (1 to 10 for crown score and 1 to 5 for node score); therefore, logistic regression was used to determine significant effects on those two response traits. Initially, an analysis was performed over the 2 years of the trial with year, the 30-year averaged climate variables, and their interactions with year as the predictor variables and the disease scores as response variables. Because of significant interactions with year, regression models were run within years using the latent factors, plus sand content, as predictor variables in logistic regression models for the response variables crown score or node score. Additional logistic model analyses were conducted using in-season climate variables as predictors and the 2008 
or 2009 crown score or node score as response variables, as described above.

\section{RESULTS}

Comparison of 30-year averages to within-season values for 2008 and 2009. Monthly precipitation for 2008 and 2009, compared with the 30-year averages, is shown in Figure 1. These monthly comparisons were made at three locations to cover the major precipitation zones of the survey. In the dry zone (Ritzville), the fall and spring of 2009 were much wetter than 2008 . Both Pendleton and Pullman also had a wetter spring in 2009 than 2008, although the relative increase was greater in the dry areas. Mean monthly temperatures were also higher in the early spring in 2008 compared with 2009 in Ritzville and Pendleton but not in Pullman (Fig. 2).

Correlations among climate variables. Several highly significant correlations were detected among the climate variables (Table 1). Elevation was negatively correlated with the temperature variables. The three temperature variables were highly intercorrelated. Precipitation was strongly positively correlated with cropping intensity, reflecting the tendency to plant annual
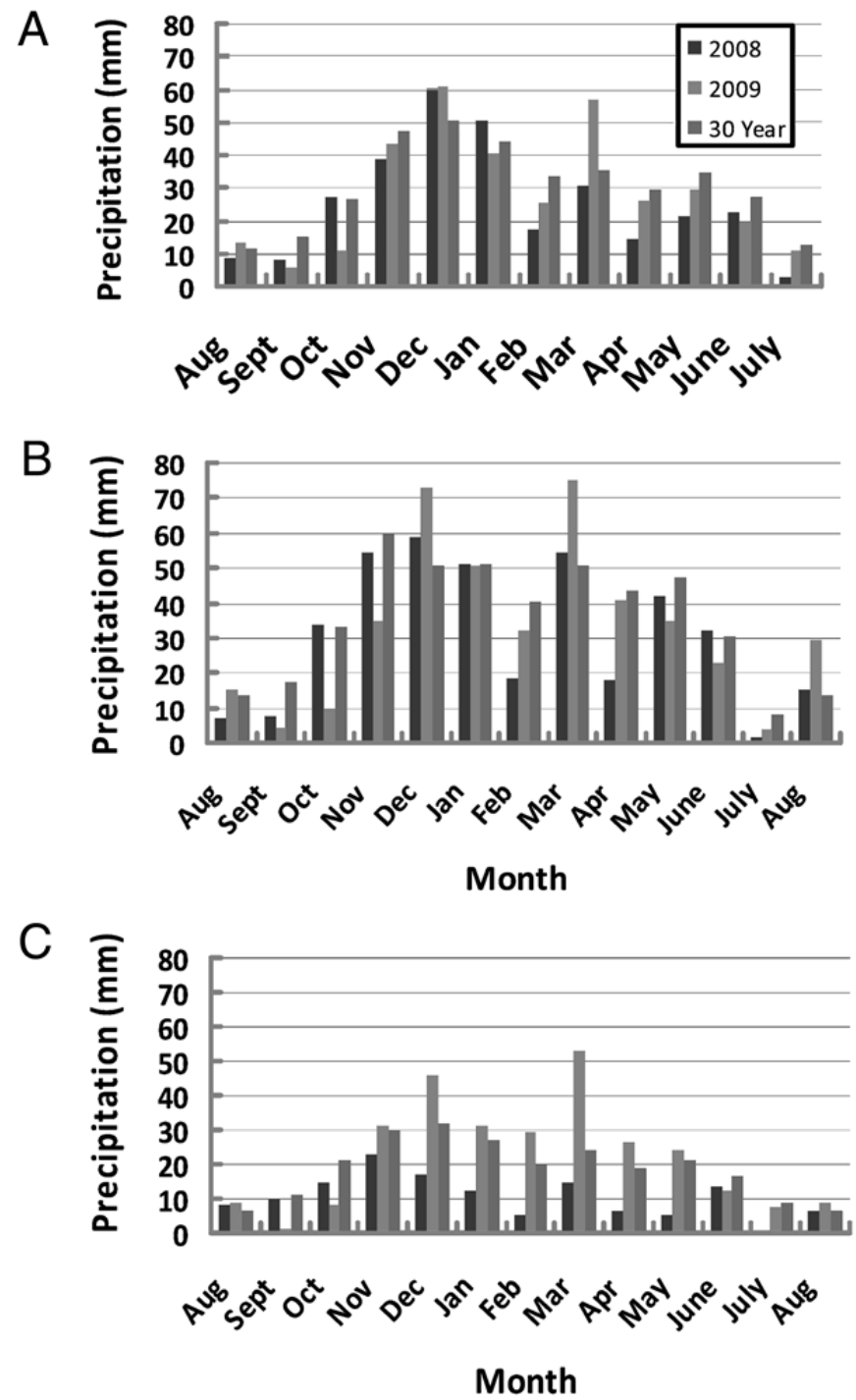

Fig. 1. Monthly average precipitation for three locations. A, Pullman (high rainfall) (factor $1=-0.27$; factor $2=1.65$ ); $\mathbf{B}$, Pendleton (moderate rainfall) (factor $1=1.05$; factor $2=0.57$ ); and $\mathbf{C}$, Ritzville (low rainfall) (factor $1=$ 0.21 ; factor $2=-1.03$ ). These locations represent three different agroclimatic regions in the Pacific Northwest. crops rather than wheat-fallow rotations with higher precipitation. The soil texture variables were not correlated with other climate variables but percent sand and percent silt were completely negatively correlated, as noted above. Cropping intensity was weakly correlated with everything except MTCM.

Subjecting the variables of the correlation matrix to factor analysis identified two latent variables, factor 1 and factor 2 (Fig. 3 ). Higher positive values of factor 1 were associated with lower elevation, lower SNOW, and higher annual temperatures, as well as higher temperatures in both the coldest and warmest months (Fig. 3). Higher positive values of factor 2 were associated with greater annual precipitation, and to a lesser extent, higher SNOW and lower MTWMs.

Species distribution. The mean frequency of isolation of F. culmorum and F. pseudograminearum was similar over both survey years (Fig. 4; Table 2). Within years, the frequency of isolation for F. pseudograminearum was slightly lower in 2009 than in 2008. Other species were also isolated from infected stems, including $F$. torulosum, $F$. acuminatum, $F$. equisiti, and $B$. sorokiniana (Table 2 ). We discovered $F$. pseudograminearum in $33 \%, F$. culmorum in $36 \%$, and both species in $26 \%$ of all fields sampled (data not shown).

$F$. culmorum was more frequently isolated from wetter and cooler locations (zones 1 and 4), whereas F. pseudograminearum occurred in significantly greater frequency in warmer zones
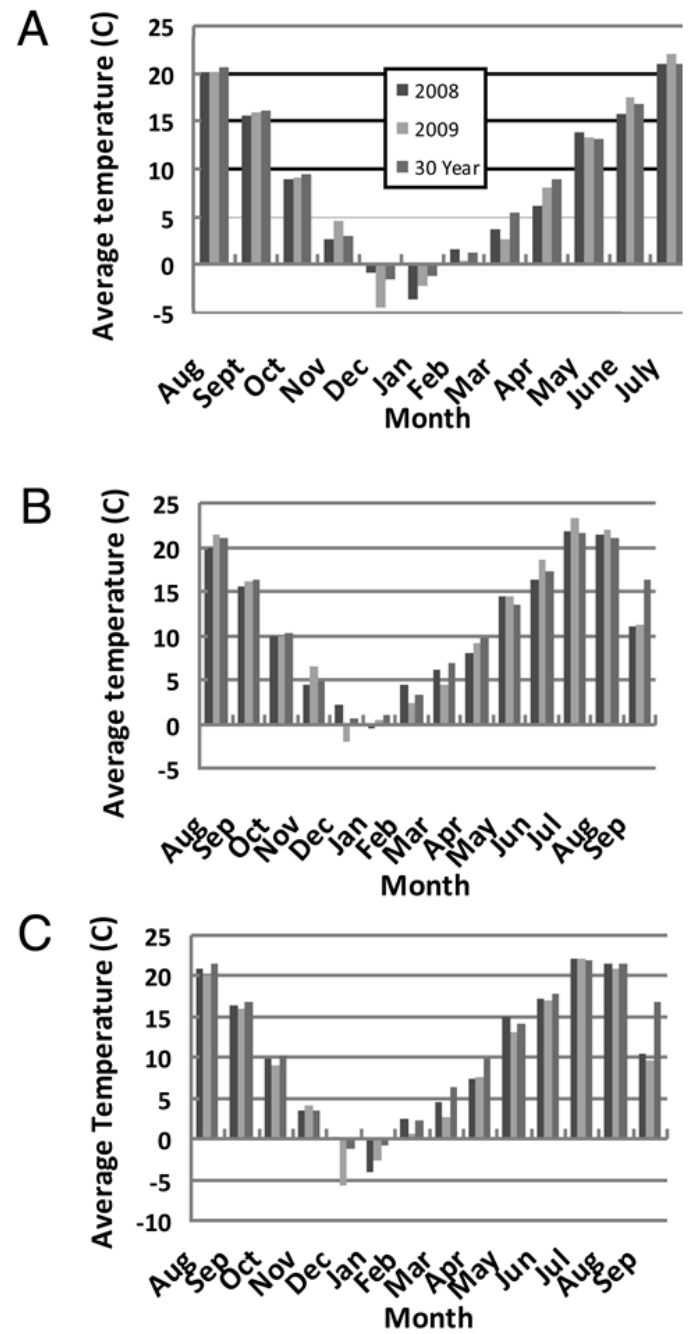

Fig. 2. Monthly average temperature for three locations. A, Pullman (high rainfall) (factor $1=-0.27$; factor $2=1.65) ; \mathbf{B}$, Pendleton (moderate rainfall) (factor $1=1.05$; factor $2=0.57$ ); and $\mathbf{C}$, Ritzville (low rainfall) (factor $1=$ 0.21 ; factor $2=-1.03$ ). These locations represent three different agroclimatic regions in the Pacific Northwest. 
(zones 3 and 5) (Fig. 4). Both species were often present within a particular field in areas of high precipitation. It is interesting to note that the isolation of $F$. pseudograminearum was negatively correlated overall with that of $F$. culmorum, showing that their distribution may not overlap in certain areas (Table 1). Also, F. pseudograminearum was positively correlated with temperature and negatively correlated with precipitation, showing that its distribution dominated in warmer and drier conditions, while F. culmorum was negatively correlated with temperature parameters, showing that its distribution dominated under cooler MAT conditions. F. culmorum was positively correlated with elevation, showing a greater abundance at higher elevations. F. culmorum was also negatively correlated with node symptoms, showing a lack of aboveground symptoms on the plants with F. culmorum infection.

In terms of environmental effects on species distribution, factor 2 was significant for the isolation of $F$. culmorum in both years (2008 and 2009) (Table 3). As factor 2 (precipitation and snowfall) increased, the probability of $F$. culmorum isolation increased from 60 to $80 \%$ in both years (Table 3; Fig. 5A and B). In 2008, there was a significant effect of factor 1 (temperature) on the isolation of $F$. pseuodgraminearum; infection increased as temperature increased (Table 4; Fig. 5C). Factor 2 was also significant in 2008 but not in 2009 for $F$. pseudograminearum isolation.

In both 2008 and 2009, there was a significant factor 2-cropping intensity interaction on the probability of $F$. culmorum isolation (Table 3). There was a decreasing probability of F. culmorum isolation as cropping intensity increased under environments with higher precipitation (Fig. 6A and C), but an increase in F. culmorum with increasing cropping intensity under low moisture conditions (Fig. 6B and D). The opposite trend was seen with $F$. pseudograminearum. F. pseudograminearum isolation in both 2008 and 2009 showed decreasing probability of infection as cropping intensity increased (Table 4), especially under low precipitation conditions (Fig. 7).

Fusarium crown disease scores. The mean FCR severity rating (rated 0 to 10) over all samples was 2.2 in 2008 and 2.9 in 2009. Ratings for FCR severity were 0.2 to 5.1 in 2008 and 0.5 to
5.4 in 2009. The mean node score (1 to 4 nodes) over all samples was 1.3 in 2008 and 1.5 in 2009 . Node score ratings were 0.7 to 1.6 in 2008 and 1.4 to 1.8 in 2009.

Fusarium crown score. Low but significant positive correlations with crown score were observed for MAT $(r=0.19 ; P=$ $0.01)$, MTCM $(r=0.30 ; P<0.0001)$, and cropping intensity $(r=$ $0.15 ; P=0.04)$ and negative correlations were observed with SNOW $(r=-0.15 ; P=0.04)$, showing increased disease severity in locations with higher temperature and lower snowfall (Table 1). In the logistic model, factor 1 was significant for crown score in $2008(P=0.002)$ and factor 2 was close to significant in 2009 $(P=0.11)$ (Table 5). For the within-season variables, MAT and

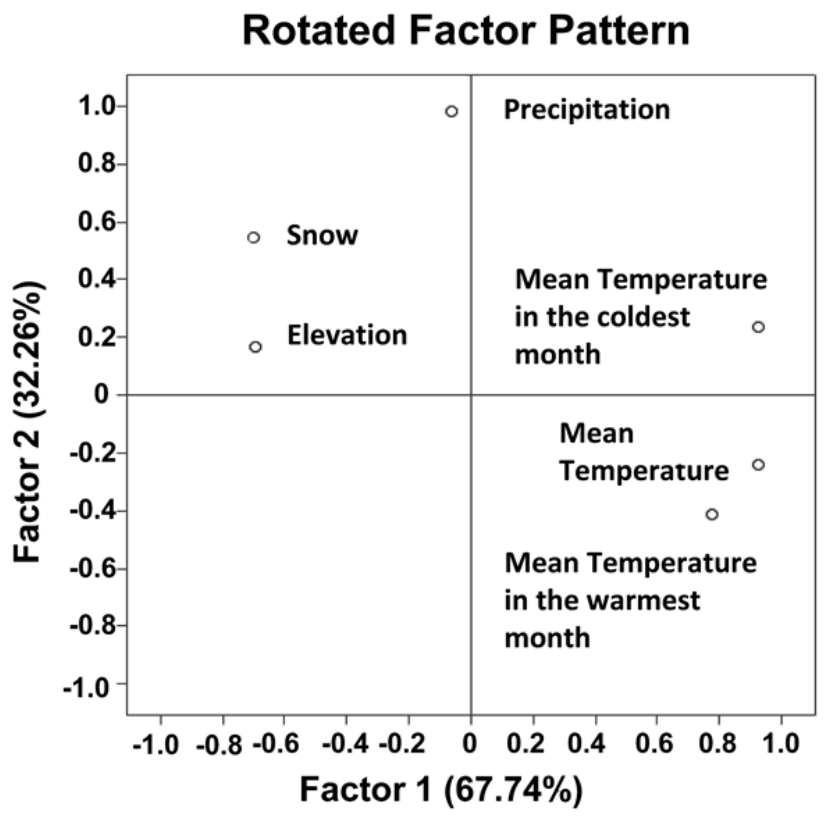

Fig. 3. Biplot of rotated factor pattern. Factor 1 explained $67.7 \%$ and factor 2 explained $32.2 \%$ of the variation among climate and geographical variables.

TABLE 1. Pearson pairwise correlations among climate and geographic field descriptors based on 2-year averages, $n=188^{\text {a }}$

\begin{tabular}{|c|c|c|c|c|c|c|c|c|c|c|c|c|}
\hline & ELEV & MAT & MAP & MTCM & MTWM & SNOW & SAND & CROP & $\mathrm{CS}$ & NODE & FP & $\mathrm{FC}$ \\
\hline ELEV & 1 & $\ldots$ & $\ldots$ & $\ldots$ & $\ldots$ & $\ldots$ & $\ldots$ & $\ldots$ & $\ldots$ & $\ldots$ & $\ldots$ & $\ldots$ \\
\hline$P$ value & $\ldots$ & $\ldots$ & $\ldots$ & $\ldots$ & $\ldots$ & $\ldots$ & $\ldots$ & $\ldots$ & $\ldots$ & $\ldots$ & $\ldots$ & $\ldots$ \\
\hline MAT & -0.57 & 1 & $\ldots$ & $\ldots$ & $\ldots$ & $\ldots$ & $\ldots$ & $\ldots$ & $\ldots$ & $\ldots$ & $\ldots$ & $\ldots$ \\
\hline$P$ value & $<0.0001$ & $\ldots$ & $\ldots$ & $\ldots$ & $\ldots$ & $\ldots$ & $\ldots$ & $\ldots$ & $\ldots$ & $\ldots$ & $\ldots$ & $\ldots$ \\
\hline MAP & 0.22 & -0.29 & 1 & $\ldots$ & $\ldots$ & $\ldots$ & $\ldots$ & $\ldots$ & $\ldots$ & $\ldots$ & $\ldots$ & $\ldots$ \\
\hline$P$ value & 0.0023 & $<0.0001$ & $\ldots$ & $\ldots$ & $\ldots$ & $\ldots$ & $\ldots$ & $\ldots$ & $\ldots$ & $\ldots$ & $\ldots$ & $\ldots$ \\
\hline MTCM & -0.49 & 0.80 & 0.14 & 1 & $\ldots$ & $\ldots$ & $\ldots$ & $\ldots$ & $\ldots$ & $\ldots$ & $\ldots$ & $\ldots$ \\
\hline$P$ value & $<0.0001$ & $<0.0001$ & 0.0654 & $\ldots$ & $\ldots$ & $\ldots$ & $\ldots$ & $\ldots$ & $\ldots$ & $\ldots$ & $\ldots$ & $\ldots$ \\
\hline MTWM & -0.56 & 0.81 & -0.44 & 0.58 & 1 & $\ldots$ & $\ldots$ & $\ldots$ & $\ldots$ & $\ldots$ & $\ldots$ & $\ldots$ \\
\hline$P$ value & $<0.0001$ & $<0.0001$ & $<0.0001$ & $<0.0001$ & $\ldots$ & $\ldots$ & $\ldots$ & $\ldots$ & $\ldots$ & $\ldots$ & $\ldots$ & $\ldots$ \\
\hline SNOW & 0.44 & -0.80 & 0.55 & -0.56 & -0.63 & 1 & $\ldots$ & $\ldots$ & $\ldots$ & $\ldots$ & $\ldots$ & $\ldots$ \\
\hline$P$ value & $<0.0001$ & $<0.0001$ & $<0.0001$ & $<0.0001$ & $<0.0001$ & $\ldots$ & $\ldots$ & $\ldots$ & $\ldots$ & $\ldots$ & $\ldots$ & $\ldots$ \\
\hline SAND & 0.09 & -0.18 & -0.09 & -0.31 & 0.03 & 0.22 & 1 & $\ldots$ & $\ldots$ & $\ldots$ & $\ldots$ & $\ldots$ \\
\hline$P$ value & 0.2329 & 0.0164 & 0.2044 & $<0.0001$ & 0.6514 & 0.003 & $\ldots$ & $\ldots$ & $\ldots$ & $\ldots$ & $\ldots$ & $\ldots$ \\
\hline CROP & 0.24 & -0.21 & 0.48 & -0.02 & -0.34 & 0.30 & -0.28 & 1 & $\ldots$ & $\ldots$ & $\ldots$ & $\ldots$ \\
\hline$P$ value & 0.0009 & 0.0032 & $<0.0001$ & 0.8088 & $<0.0001$ & $<0.0001$ & 0.0001 & $\ldots$ & $\ldots$ & $\ldots$ & $\ldots$ & $\ldots$ \\
\hline $\mathrm{CS}$ & -0.14 & 0.19 & 0.23 & 0.30 & 0.10 & -0.15 & -0.22 & 0.15 & 1 & $\ldots$ & $\ldots$ & $\ldots$ \\
\hline$P$ value & 0.0581 & 0.0086 & 0.0018 & $<0.0001$ & 0.1646 & 0.0434 & 0.0024 & 0.0408 & $\ldots$ & $\ldots$ & $\ldots$ & $\ldots$ \\
\hline NODE & -0.23 & 0.28 & 0.28 & 0.41 & 0.13 & -0.17 & -0.25 & 0.24 & 0.85 & 1 & $\ldots$ & $\ldots$ \\
\hline$P$ value & 0.0016 & 0.0001 & 0.0001 & $<0.0001$ & 0.0813 & 0.0221 & 0.0006 & 0.0009 & $<0.0001$ & $\ldots$ & $\ldots$ & $\ldots$ \\
\hline FP & -0.27 & 0.34 & -0.13 & 0.34 & 0.26 & -0.27 & -0.11 & -0.18 & 0.08 & 0.04 & 1 & $\ldots$ \\
\hline$P$ value & 0.0002 & $<0.0001$ & 0.0837 & $<0.0001$ & 0.0004 & 0.0002 & 0.1474 & 0.0166 & 0.2505 & 0.6115 & $\ldots$ & $\ldots$ \\
\hline $\mathrm{FC}$ & 0.36 & -0.38 & 0.05 & -0.44 & -0.31 & 0.26 & 0.16 & 0.00 & -0.28 & -0.30 & -0.57 & 1 \\
\hline$P$ value & $<0.0001$ & $<0.0001$ & 0.4651 & $<0.0001$ & $<0.0001$ & 0.0003 & 0.0275 & 0.9699 & 0.0001 & $<0.0001$ & $<0.0001$ & $\ldots$ \\
\hline
\end{tabular}

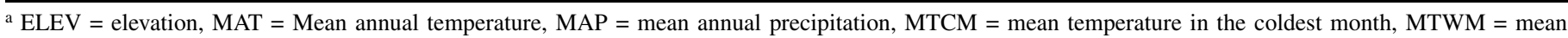
temperature in the warmest month, $\mathrm{CROP}=$ cropping intensity $(100 \%=$ high intensity with annual cropping $), \mathrm{SNOW}=$ annual snowfall, $\mathrm{SAND}=$ percent sand, $\mathrm{CS}=$ crown score, $\mathrm{NODE}=$ node rating, $\mathrm{FP}=$ Fusarium pseudograminearum incidence per field per five samples, and $\mathrm{FC}=$ Fusarium culmorum incidence per field per five samples. 
MTWM were almost significant in $2008(P=0.09)$, while MAP was significant in $2009(P=0.002)$, results which closely resembled the 30 -year historical data variables that went into the factors. The increase in crown score with factor 1 in 2008 is shown in Figure 8A and the increase in crown score with precipitation in 2009 is shown in Figure 9A.

Node symptom rating. Significant positive correlations with node score were observed with MAT and MAP $(r=0.28$, $P=0.001)$, MTCM $(r=0.41, P<0.0001)$, and cropping intensity $(r=0.24, P=0.009)$, with negative correlations for elevation $(r=$ $-0.23, P=0.0016)$ and SNOW $(r=-0.17, P=0.02)$ (Table 1$)$. This indicates that higher node scores are present in areas with higher temperature and total precipitation but less in cool areas with higher elevations and more snow. In the logistic model, factor 1 was significant for node score in 2008 and MAP in season was significant in 2009 (Table 6). The increase in node score with factor 1 in 2008 is shown in Figure 8B and the increase in node score with precipitation in 2009 is shown in Figure 9B.

\section{DISCUSSION}

Climate studies tend to be conducted with foliar pathogens of wheat, such as Fusarium head blight, due to the requirement for suitable temperature and moisture on the leaf surface needed for germination of spores and infection (49). Few studies have examined the distribution of soilborne or residue-borne pathogens

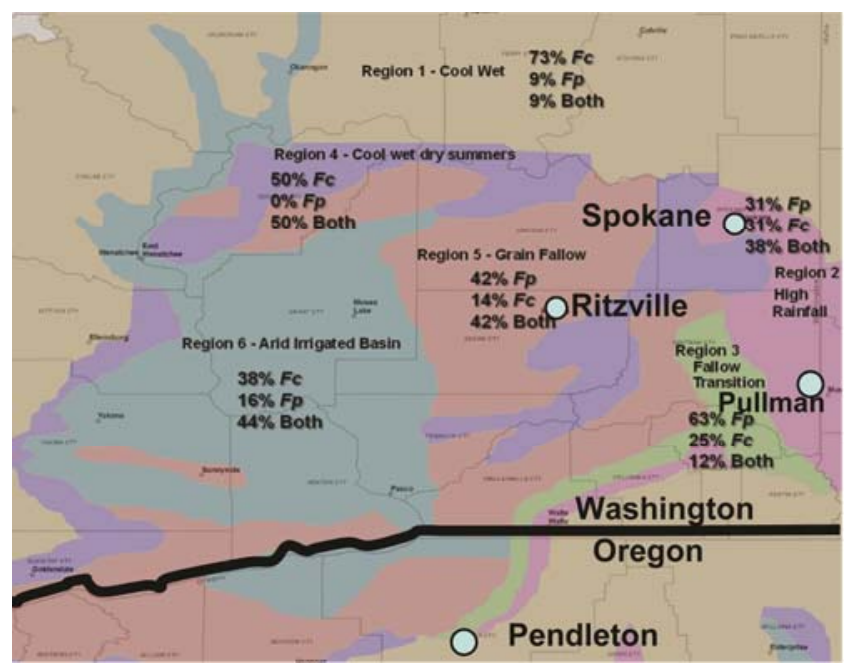

Fig. 4. Six agronomic zones for the dryland Pacific Northwest developed by Douglas et al. (16) on the basis of precipitation, growing degree days, and soil type. Agronomic regional zones are depicted by color polygons: region 1 (tan), region 2 (pink), region 3 (green), region 4 (purple), region 5 (red), and region 6 (blue).

TABLE 2. Frequency of isolation of each respective species from the total $(n=525)$ sampled wheat stems

\begin{tabular}{lccc}
\hline & \multicolumn{3}{c}{ Frequency of isolation $^{\mathrm{b}}$} \\
\cline { 2 - 4 } Fungal species $^{\mathrm{a}}$ & 2008 & 2009 & Mean $^{\mathrm{c}}$ \\
\hline Fusarium pseudograminearum & 34 & 26 & 30 \\
F. culmorum & 38 & 23 & 31 \\
F. torulosum & 12 & 14 & 13 \\
F. acuminatum & 2 & 1 & 1 \\
F. equisiti & 1 & 0 & 0 \\
Bipolaris sorokiniana & 1 & 2 & 2 \\
\hline
\end{tabular}

${ }^{a}$ Fungal species were identified according to Burgess et al. (9). Stem isolates were cultured from Synthetischer Nährstoffärmer agar media and placed on slides for morphological identification.

${ }^{b}$ Frequency of isolations represent the proportion of samples (per 525) isolated from the entire survey for 2008 and 2009 survey years, respectively.

${ }^{c}$ Mean represents the average for each species isolated across the 2008 and 2009 survey years. across a large geographical region and attempted to relate populations and disease to climatic and geographic variables $(2,3)$. Cook (12) reported that the distribution of $F$. pseudograminearum and $F$. culmorum was linked to geographical county locations. Others have reported that monthly temperature, elevation, and other climate parameters significantly affect the distribution of Fusarium spp. (2,27,39,43).

Douglas et al. $(15,16)$ classified the PNW dryland wheat production region into six agronomic ecological zones (agroecozones), primarily on the basis of temperature, precipitation, and soil depth. When we related disease and the distribution of $F$. pseudograminearum and $F$. culmorum to these agroecozones, we found the highest FCR scores in zone 3 (fallow-transition) but other areas showed moderate levels of disease which varied between the 2 years, making it difficult to establish a trend. The incidence of fields with both species ranged from 9 to $50 \%$ among climate zones, making it difficult to say which species was more predominant. F. culmorum occurred alone in $73 \%$ of the fields in zone 1 (cool and wet) and in $50 \%$ of zone 4 (cool and dry), characterized by cooler winter temperatures and a higher elevation, whereas F. pseudograminearum occurred alone in $63 \%$ of the fields in zone 3 (fallow-transition) and $42 \%$ of the fields in zone 5 (grain-fallow) (Fig. 4) (31).

One of the difficulties with these agroecozone classifications is that they combine both precipitation and temperature into categories with definitive geographic boundaries but without the ability to account for gradients or variation within a zone. With the development of geographic information systems and satellite imagery, we can now examine these continuous climate and geographical variables with a much higher degree of resolution across a continuous gradient rather than using categorical geographical-based zones. The strength of the factor analysis approach using 30-year average data is the ability to classify each field with a factor score associated with a range of climatic conditions, thus increasing the resolution for making climatic comparisons.

The climate data sets used in this study are available at spatial resolutions of $4 \mathrm{~km}$ (1) and $1 \mathrm{~km}(34)$, allowing an approximation for each sampling location. The development of the crop layer

TABLE 3. Tests of effects from logistic regression analysis of Fusarium culmorum from collected stems in the Pacific Northwest during 2008 and 2009

\begin{tabular}{lccccc}
\hline & \multicolumn{2}{c}{2008} & & \multicolumn{2}{c}{2009} \\
\cline { 2 - 3 } \cline { 5 - 6 } Parameter & Wald $\chi^{2}$ & $P$ value & & Wald $\chi^{2}$ & $P$ value \\
\hline Intercept $^{\mathrm{a}}$ & 0.23 & 0.63 & & 4.10 & 0.04 \\
Factor 1 & 1.89 & 0.17 & & 0.03 & 0.87 \\
Factor 2 & 11.51 & 0.0007 & & 6.11 & 0.01 \\
Factor 1 $\times$ factor 2 & 0.26 & 0.61 & & 0.84 & 0.36 \\
SAND & 0.01 & 0.94 & & 0.28 & 0.60 \\
Factor 1 $\times$ SAND & 0.85 & 0.36 & & 0.07 & 0.79 \\
Factor 2 $\times$ SAND & 0.57 & 0.45 & & 9.61 & 0.0019 \\
CROP & 1.25 & 0.26 & & 0.00 & 0.97 \\
Factor 1 $\times$ CROP & 0.03 & 0.86 & & 1.89 & 0.17 \\
Factor 2 $\times$ CROP & 10.43 & 0.0012 & & 9.58 & 0.002 \\
Intercept & 18.57 & $<0.0001$ & & 3.66 & 0.05 \\
MAT in season & 24.74 & $<0.0001$ & & 1.97 & 0.16 \\
MAP in season & 13.57 & 0.0002 & & 2.13 & 0.14 \\
MTWM in season & 28.80 & $<0.0001$ & & 0.13 & 0.72 \\
MTCM in season & 0.01 & 0.91 & & 0.16 & 0.69 \\
SNOW in season & 5.83 & 0.02 & & 0.26 & 0.61 \\
\hline
\end{tabular}

a Factor 1 = first factor from analysis described by temperature, factor $2=$ second factor from factor analysis described by precipitation, MAT = mean annual temperature, $\mathrm{MAP}=$ mean annual precipitation, $\mathrm{MTCM}=$ mean temperature in the coldest month MTWM = mean temperature in the warmest month, CROP = cropping intensity, SNOW = annual snowfall, and SAND = percent sand.

b Within-season variables were included in a separate logistic regression model for within-season (2008 and 2009) MAT, MAP, MTCM, MTWM, and SNOW. 
data set from the National Agricultural Statistics Service based on high-resolution satellite imagery provided us with a cropping intensity variable, based on a model of cropping intensity derived from all the surrounding fields in a $4-$ to $10-\mathrm{km}$ area. Thus, dataintensive models were used to describe how these climatic and cropping factors influence pathogen distribution.

Climate is highly variable across the regions and locations we surveyed throughout the PNW, with several measured parameters available from weather stations. How does one sort out which are important and which may have biological relevance? A number of multivariate techniques have been used in the plant pathology literature to answer these questions. Correlation models have often been used to identify weather or climate variables that are associated with disease. For example, Smiley (44) used simple correlations and showed a negative correlation between precipitation and FCR severity in winter wheat in a wheat-summer fallow system in Oregon, and a stronger positive correlation with temperature. The strongest negative correlation was with the ordinal day of planting (i.e., more disease with early planting in the fall), which supported a well-known understanding among growers that later plantings have less disease. Another approach has been to use multiple regressions to develop predictive models. For example, the most important factor affecting eyespot infection in wheat was the number of days with rainfall $>3 \mathrm{~mm}$ in October to April (24). Eyespot is also a crown disease, caused by the fungus $O$. yallundae and $O$. acuformis (22). lying our observed variables and decided to use a factor analysis
We theorized that latent factors related to climate were under-

TABLE 4. Tests of effects from logistic regression analysis of Fusarium pseudograminearum from collected stems in the Pacific Northwest during 2008 and 2009

\begin{tabular}{|c|c|c|c|c|}
\hline \multirow[b]{2}{*}{ Parameter } & \multicolumn{2}{|c|}{2008} & \multicolumn{2}{|c|}{2009} \\
\hline & Wald $\chi^{2}$ & $P$ value & Wald $\chi^{2}$ & $P$ value \\
\hline Intercept $^{\mathrm{a}}$ & 0.59 & 0.43 & 0.19 & 0.67 \\
\hline Factor 1 & 5.63 & 0.02 & 0.08 & 0.78 \\
\hline Factor 2 & 11.32 & 0.0008 & 1.78 & 0.18 \\
\hline Factor $1 \times$ factor 2 & 0.02 & 0.90 & 0.00 & 0.98 \\
\hline Sand & 0.10 & 0.75 & 1.49 & 0.22 \\
\hline Factor $1 \times$ SAND & 2.12 & 0.15 & 3.87 & 0.05 \\
\hline Factor $2 \times$ SAND & 1.93 & 0.16 & 3.28 & 0.07 \\
\hline CROP & 5.66 & 0.02 & 4.21 & 0.04 \\
\hline Factor $1 \times$ CROP & 2.10 & 0.15 & 0.32 & 0.57 \\
\hline Factor $2 \times$ CROP & 9.27 & 0.002 & 2.56 & 0.11 \\
\hline Intercept ${ }^{b}$ & 7.74 & 0.005 & 0.09 & 0.76 \\
\hline MAT in season & 5.39 & 0.02 & 2.02 & 0.16 \\
\hline MAP in season & 12.37 & 0.0004 & 0.84 & 0.36 \\
\hline MTWM in season & 7.34 & 0.006 & 0.67 & 0.41 \\
\hline MTCM in season & 0.49 & 0.49 & 0.08 & 0.78 \\
\hline SNOW in season & 0.13 & 0.72 & 0.00 & 0.99 \\
\hline
\end{tabular}

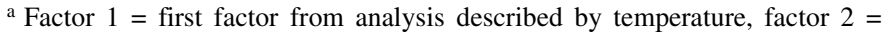
second factor from factor analysis described by precipitation, MAT $=$ Mean annual temperature, MAP = mean annual precipitation, $\mathrm{MTCM}=$ mean temperature in the coldest month MTWM = mean temperature in the warmest month, CROP = cropping intensity, SNOW = annual snowfall, and $\mathrm{SAND}=$ percent sand.

b Within-season variables were included in a separate logistic regression model for within-season (2008 and 2009) MAT, MAP, MTCM, MTWM, and SNOW.
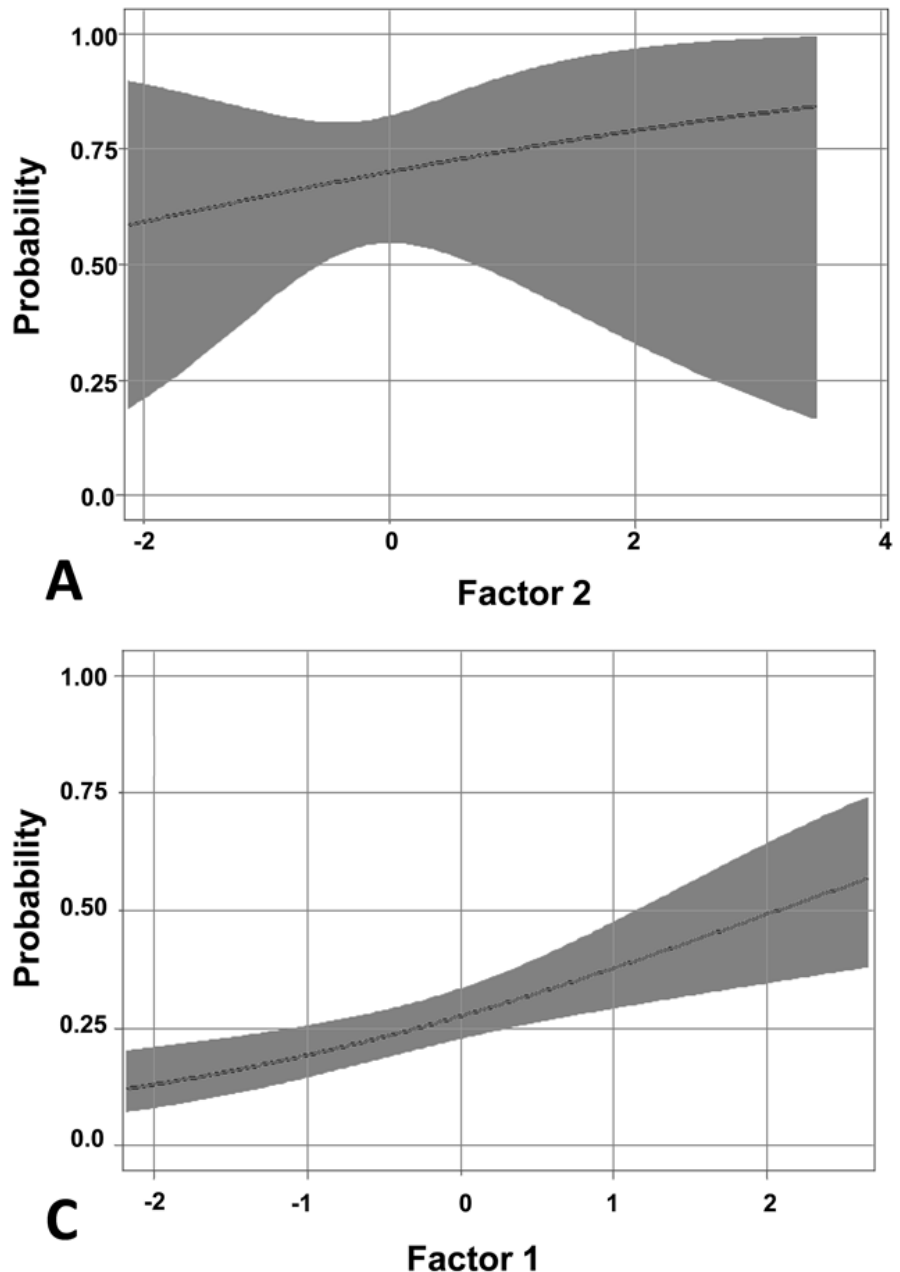

\section{B}
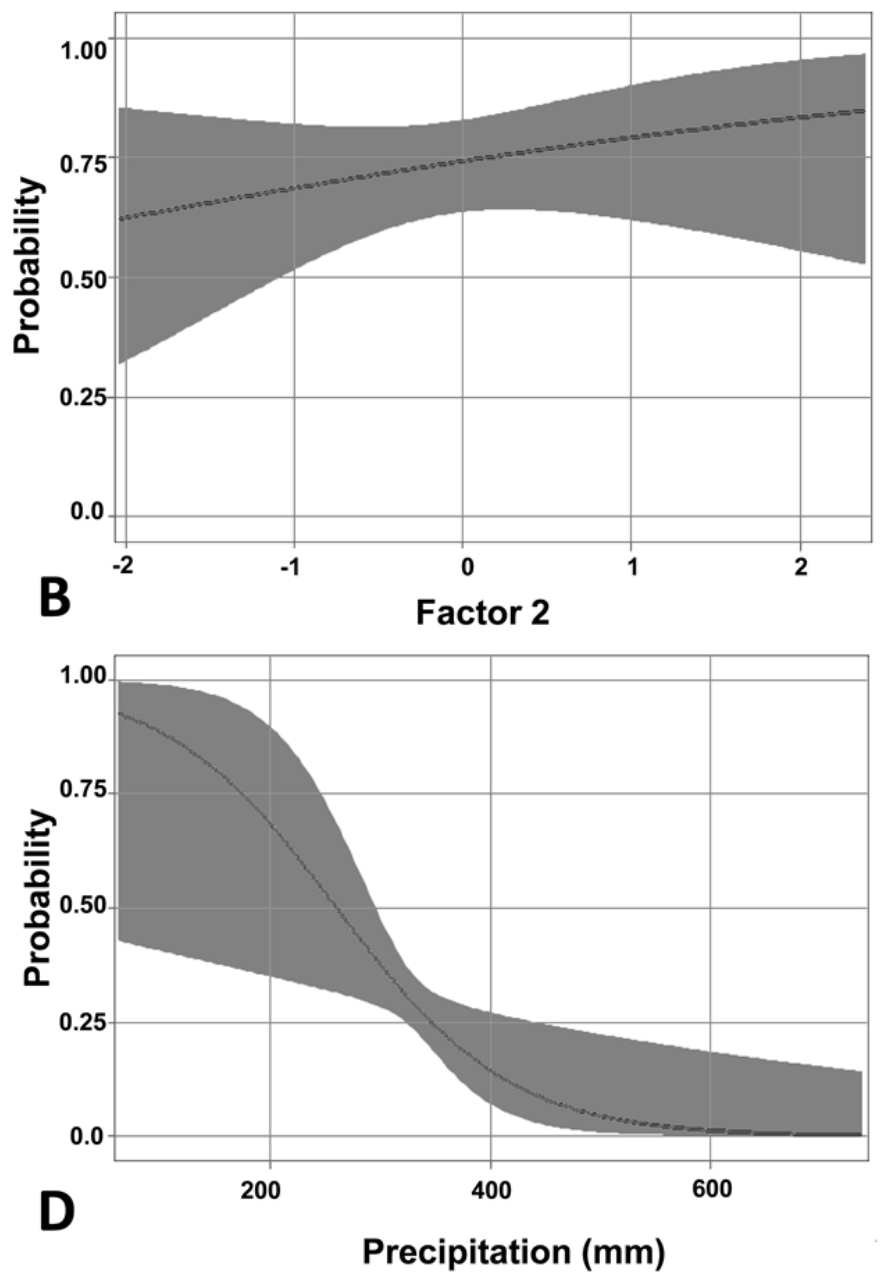

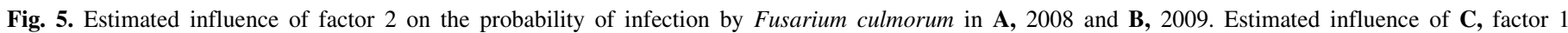

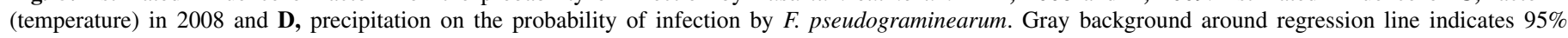
confidence limits. 
approach to reduce these variables to latent factors that could be regressed against disease parameters (48). Using factor analysis, we constructed two latent factors: factor 1 , based primarily on temperature and elevation, and factor 2, based on precipitation, snowfall, and elevation. Both temperature and precipitation explained much of the variability in the climate of our field sites (4). Several important and significant trends were identified from this research.

There was a significant difference between years 2008 and 2009 for crown score, node, and the isolation of F. pseudograminearum, whereas there were similarities between years in the levels of $F$. culmorum isolations and their interactions with environmental and cropping intensity patterns. The first weather difference between years to note is that 2008 was characterized by warmer temperatures in February, March, and May (greater than the 30-year average) than that of 2009, especially in the drier areas. An increase in FCR scores and F. pseuodgraminearum isolations was associated with increasing values of factor 1 (largely defined by increasing temperature). May in the PNW is a critical time period in plant development, where plants are typically under water stress during grain development that has been known to be a time period associated with FCR infection (14). Crown score, node symptoms, and the levels of $F$. pseudograminearum increased in locations with higher mean temperature, a trend that was significant only in 2008. Plants are predisposed to more intense development of FCR when under drought stress $(29,40$, 44). Increased temperature increases transpiration and plants more quickly deplete the stored moisture (29). The authors be- lieved that this difference between years for these parameters was due to higher spring temperatures in 2008 leading to greater crown rot disease severity (in crowns and nodes). Our research and others have noted that there are significant correlations between $F$. pseudograminearum levels and crown rot severity ratings. The linkage between FCR disease ratings and F. pseudogrami-

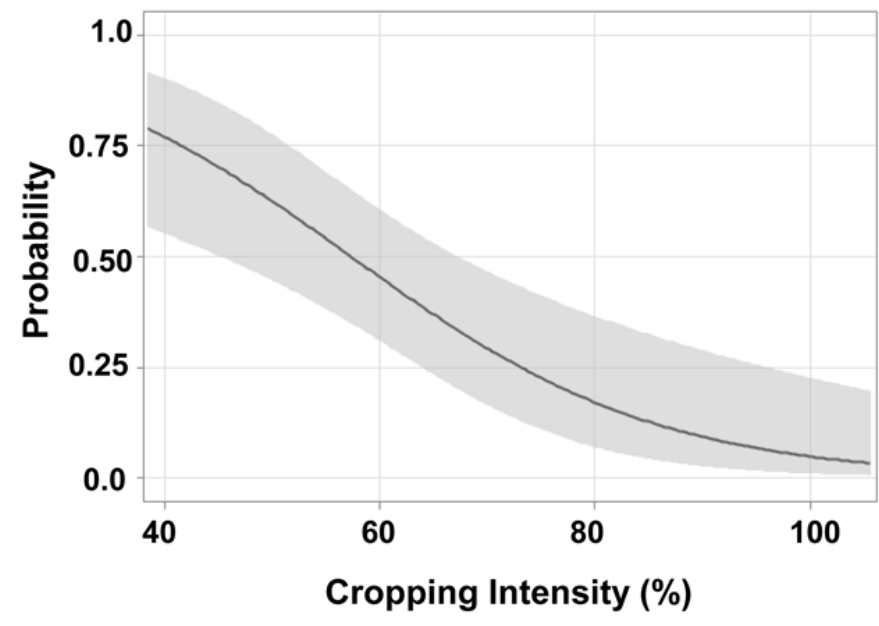

Fig. 7. Relationship between cropping intensity and the probability of infection by Fusarium pseudograminearum under low levels of factor 2 in 2008.
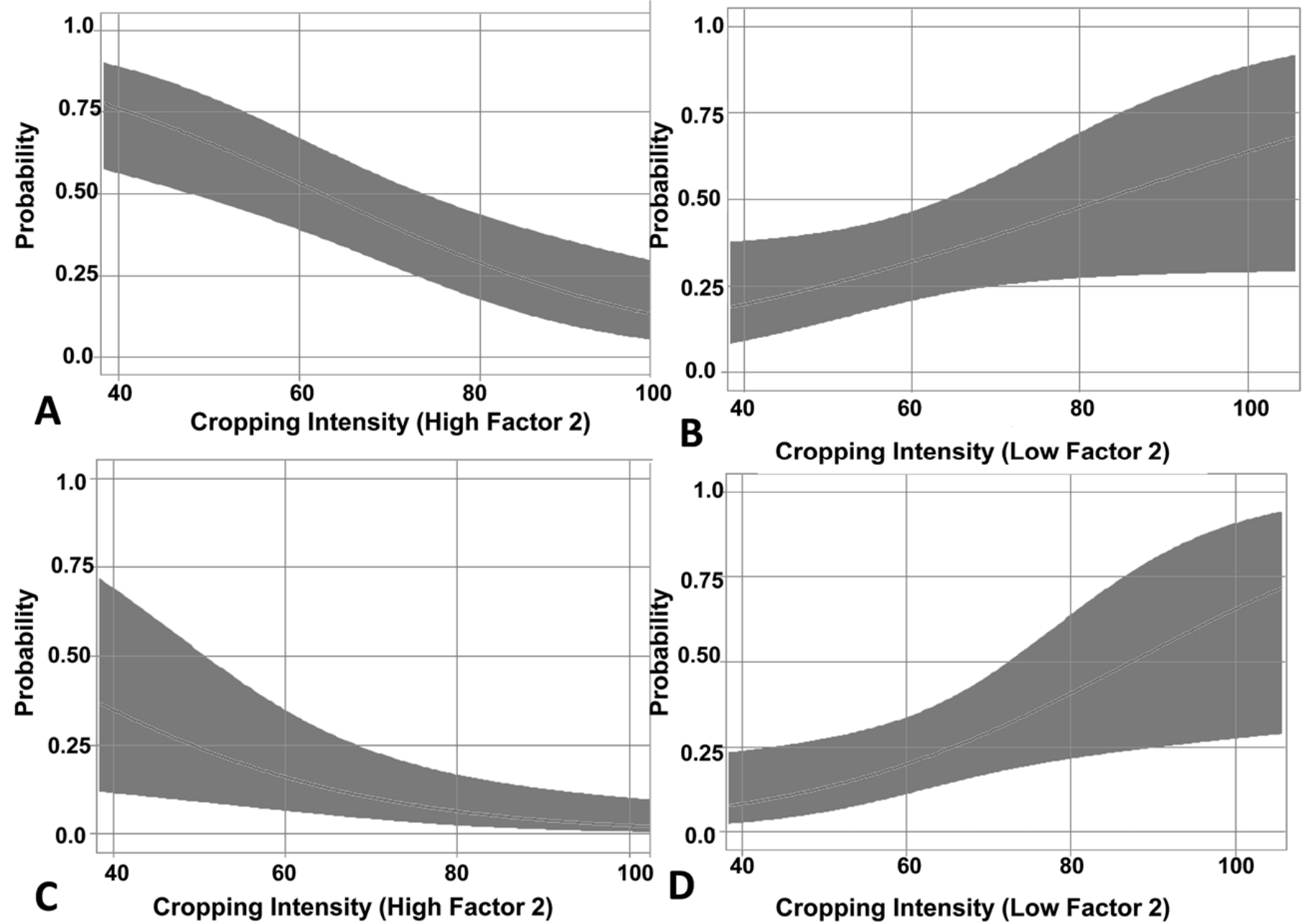

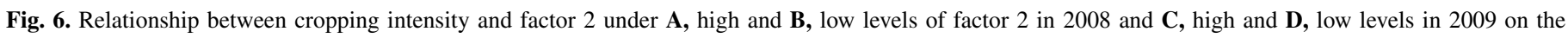
probability of infection by Fusarium culmorum. Gray background around regression line indicates $95 \%$ confidence limits. 
TABLE 5. Tests of effects from logistic regression analysis of Fusarium crown rot crown score from collected stems in the Pacific Northwest during 2008 and 2009

\begin{tabular}{|c|c|c|c|c|}
\hline \multirow[b]{2}{*}{ Parameter } & \multicolumn{2}{|c|}{2008} & \multicolumn{2}{|c|}{2009} \\
\hline & Wald $\chi^{2}$ & $P$ value & Wald $\chi^{2}$ & $P$ value \\
\hline Intercept $^{\mathrm{a}}$ & 228.97 & $<0.0001$ & 137.63 & $<0.0001$ \\
\hline Factor 1 & 9.39 & 0.002 & 1.64 & 0.20 \\
\hline Factor 2 & 0.64 & 0.42 & 2.55 & 0.11 \\
\hline Factor $1 \times$ factor 2 & 0.52 & 0.47 & 3.10 & 0.08 \\
\hline Sand & 0.02 & 0.88 & 0.46 & 0.50 \\
\hline Factor $1 \times$ SAND & 0.02 & 0.88 & 0.00 & 0.98 \\
\hline Factor $2 \times$ SAND & 1.67 & 0.20 & 0.57 & 0.45 \\
\hline Intercept ${ }^{\mathrm{b}}$ & 0.29 & 0.59 & 3.46 & 0.06 \\
\hline MAT in season & 2.82 & 0.09 & 0.06 & 0.80 \\
\hline MAP in season & 1.94 & 0.16 & 9.39 & 0.002 \\
\hline MTWM in season & 2.85 & 0.09 & 0.22 & 0.64 \\
\hline MTCM in season & 0.74 & 0.39 & 0.55 & 0.46 \\
\hline SNOW in season & 2.01 & 0.16 & 0.80 & 0.37 \\
\hline
\end{tabular}

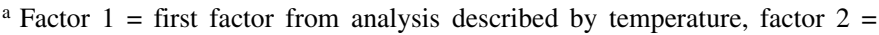
second factor from factor analysis described by precipitation, MAT $=$ Mean annual temperature, MAP $=$ mean annual precipitation, $\mathrm{MTCM}=$ mean temperature in the coldest month, MTWM = mean temperature in the warmest month, CROP $=$ cropping intensity, $\mathrm{SAND}=$ percent sand, and SNOW = annual snowfall.

b Within-season variables were included in a separate logistic regression model for within-season (2008 and 2009) MAT, MAP, MTCM, MTWM, and SNOW.

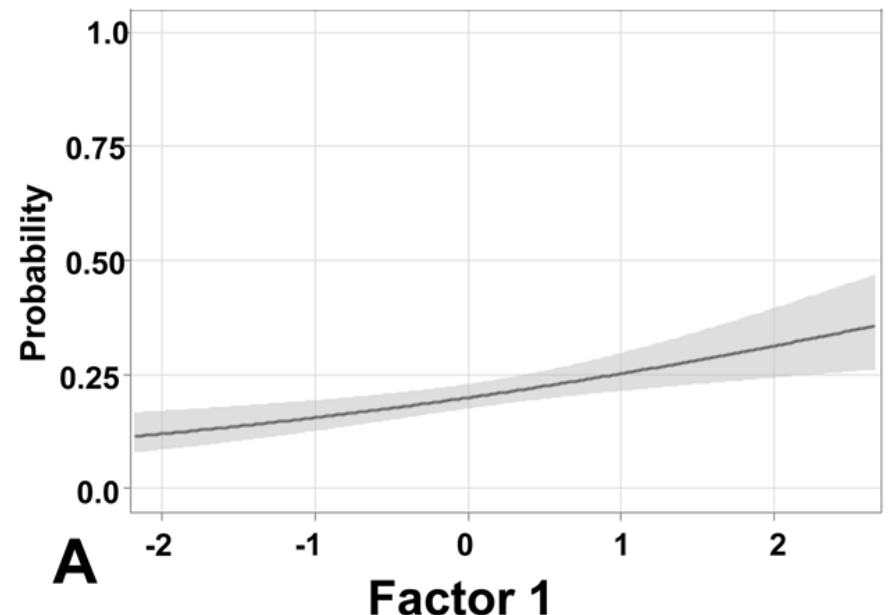

nearum at higher temperatures levels agrees with that of others $(2,3,8,10,14,27,40,41,43)$.

The second weather difference to note between the years is that spring precipitation (February to May) was considerably greater in 2009 than 2008, especially in the drier areas. The lack of significant crown score, node symptoms, and $F$. pseudograminearum isolations in 2009 agrees with the fact that these symptoms are associated with warmer and drier spring conditions that were more typical of $2008(8,12-14)$. However, it appears that the significant association of $F$. culmorum isolations between factor 2 and MAP was significant in both 2008 and 2009, showing more consistency in this species occurrence across years. This trend seemed to be stronger in 2008 than 2009, again probably due to drier spring conditions in 2008. Likewise, the increase in significant effects of $F$. culmorum isolations under these conditions also agrees with that of others, that F. culmorum is found under cooler and wetter conditions. However, this difference may be more defined by regions rather than years because $F$. culmorum isolations increased significantly in locations with increasing levels of factor 2 (defined by increasing precipitation) $(2-4,8)$.

Although mean annual precipitation varied across our field sample sites, winter precipitation followed by terminal drought and heat stress during wheat ripening was common throughout. It is likely that larger plants were produced in areas with higher annual precipitation, resulting in plants with more tillers that

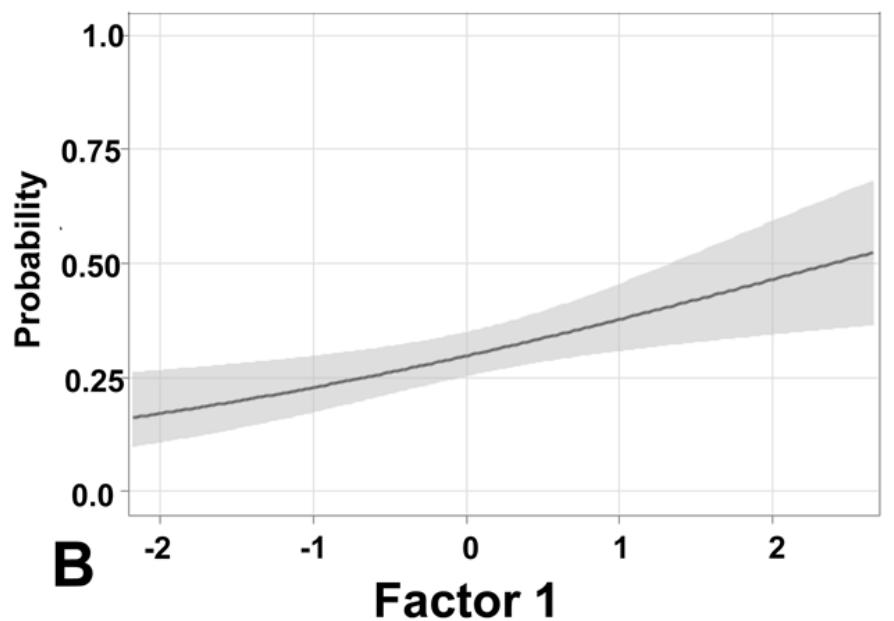

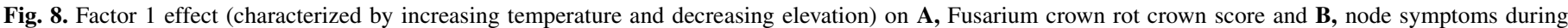
2008. Gray background around regression line indicates $95 \%$ confidence limits.
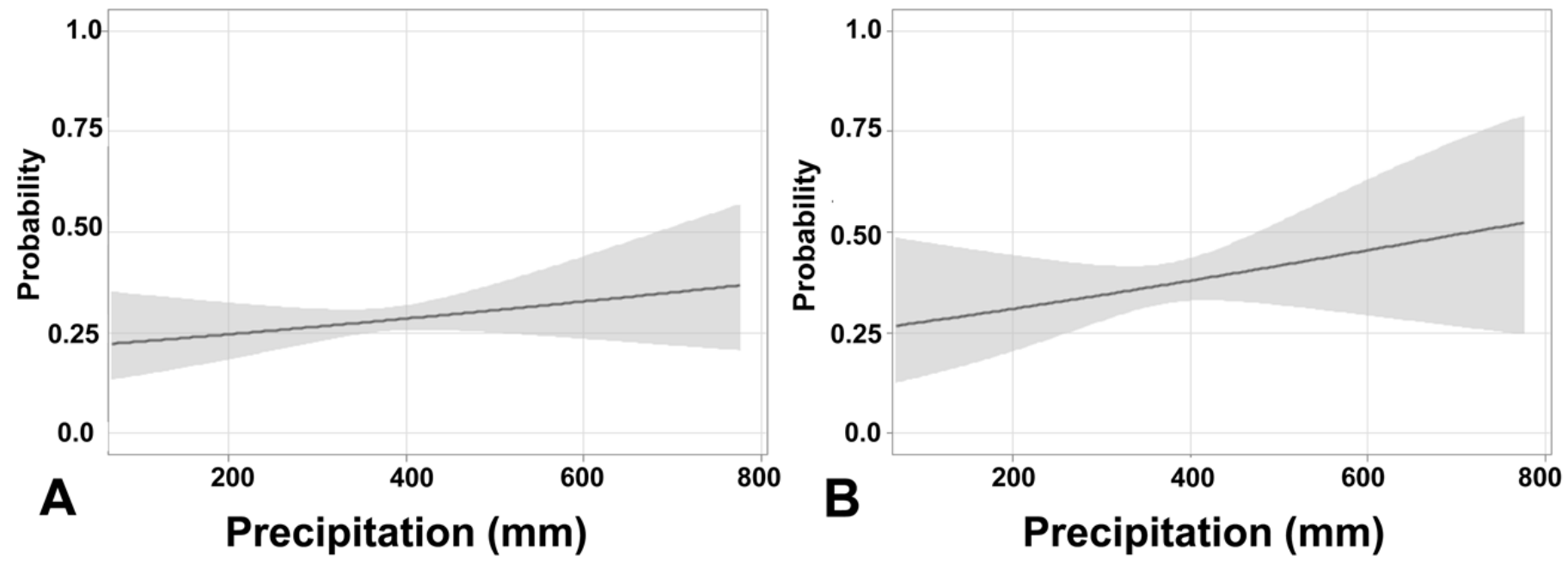

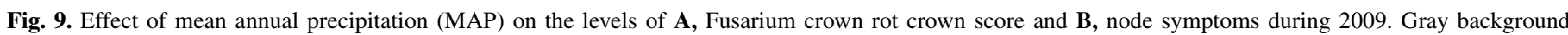
around regression line indicates $95 \%$ confidence limits. 
depleted terminal moisture, causing stress and more evidence of FCR disease development. Likewise, plant density per unit of area is greater in higher-precipitation regions because seed is planted at lower densities in rows spaced at $\approx 41-\mathrm{cm}$ intervals in lowprecipitation areas and at higher densities in rows spaced at $\approx 25$-cm intervals in higher-precipitation areas.

The third major finding in this study was the association of Fusarium spp. isolation with environmental and cropping intensity parameters. Again, F. culmorum isolation interactions with factor 2 and cropping intensity levels were consistent across 2008 and 2009. Under low levels of factor 2 (i.e., low precipitation), isolations of $F$. culmorum increased with increasing cropping intensity (i.e., more crop rotation) while those of $F$. pseudograminearum decreased. F. pseudograminearum is known to survive mainly as hyphae in residue, whereas F. culmorum originates more from chlamydospores with a greater chance of survival under crop rotation $(8,19,39)$. These trends could also be correlated with greater crop residue amounts in higher-precipitation areas, or higher levels of $\mathrm{N}$ applied to increase grain protein of hard red wheat varieties, which have been planted on increasing acreage since 2000. Backhouse and Burgess (3) found similar trends with increases in distribution of $F$. pseudograminearum in warmer drier areas.

Year-to-year variation between species occurrence has been documented previously $(3,4,8,13,27,39,41,43,44)$. A factor that could affect species distribution across the PNW is the inoculum source and overwintering structures. F. pseudograminearum and $F$. culmorum survive as chlamydospores in the soil and host residue. However, the survival of $F$. culmorum chlamydospores (8.5 years) has been reported to be much longer than that of F. pseudograminearum (5.5 years) (39). A greater decrease in F. culmorum chlamydospores occurred over time at Lind, WA in the dry, wheat-fallow region (survived 215 days) compared with Pullman, WA in the higher-precipitation annual-cropping region (survived 330 days) but field surveys indicated greater disease severity at Lind than Pullman (19). Environmental conditions had a greater influence than chlamydospore survival on the ability of the fungus to develop and persist as a pathogen.

Our most interesting finding, evident in both years, was that F. culmorum was more frequently isolated from cooler locations and at higher elevations, areas that experience significant amounts of snowfall, whereas $F$. pseudograminearum occurred in signifi-

TABLE 6. Tests of effects from logistic regression analysis of node symptoms from collected stems in the Pacific Northwest during 2008 and 2009

\begin{tabular}{lccccc}
\hline & \multicolumn{2}{c}{2008} & & \multicolumn{2}{c}{2009} \\
\cline { 2 - 3 } \cline { 5 - 6 } Parameter & Wald $\chi^{2}$ & $P$ value & & Wald $\chi^{2}$ & $P$ value \\
\hline Intercept $^{\mathrm{a}}$ & 48.08 & $<0.0001$ & & 23.20 & $<0.0001$ \\
Factor 1 & 7.07 & 0.007 & & 2.02 & 0.16 \\
Factor 2 & 0.30 & 0.58 & & 3.61 & 0.06 \\
Factor 1 $\times$ factor 2 & 0.94 & 0.33 & & 0.51 & 0.48 \\
SAND & 0.00 & 0.98 & & 0.07 & 0.79 \\
Factor 1 × SAND & 0.01 & 0.94 & & 0.22 & 0.64 \\
Factor 2 $\times$ SAND & 0.62 & 0.43 & & 1.07 & 0.30 \\
Intercept & 0.63 & 0.43 & & 1.18 & 0.28 \\
MAT in season & 1.96 & 0.16 & & 0.02 & 0.90 \\
MAP in season & 0.40 & 0.53 & & 6.31 & 0.01 \\
MTWM in season & 2.09 & 0.15 & & 0.27 & 0.60 \\
MTCM in season & 0.16 & 0.69 & & 0.00 & 0.95 \\
SNOW in season & 0.55 & 0.46 & & 0.29 & 0.59
\end{tabular}

${ }^{\mathrm{a}}$ Factor 1 = first factor from analysis described by temperature, factor $2=$ second factor from factor analysis described by precipitation, MAT $=$ Mean annual temperature, MAP $=$ mean annual precipitation, $\mathrm{MTCM}=$ mean temperature in the coldest month, MTWM = mean temperature in the warmest month, CROP = cropping intensity, SAND = percent sand, and SNOW = annual snowfall.

b Within-season variables were included in a separate logistic regression model for within-season (2008 and 2009) MAT, MAP, MTCM, MTWM, and SNOW. cantly greater frequency in warmer, lower elevations. The analysis showed that temperature and cropping intensity played a more important role in $F$. pseudograminearum distribution and infection. With an increase in factor 1 components, defined by higher temperature and lower elevation, the probability of $F$. pseudograminearum increased. The dominance of Fusarium spp. also has changed over time in the crown rot complex. Cook (12) reported that $90 \%$ of the species isolated from the PNW were $F$. culmorum but $F$. pseudograminearum ( $F$. roseum $\mathrm{f}$. $\mathrm{sp}$. cerealis Graminearum) dominated in Franklin, Walla Walla, and Benton counties in southern Washington. Both our survey and that of Smiley and Patterson (43) isolated a higher frequency of $F$. pseudograminearum throughout the PNW region.

Results of the current study agree with others that F. pseudograminearum and $F$. culmorum are associated with crown rot and can be found throughout the rain-fed dryland wheat production region of the PNW $(12-14,41,43)$. The differences in the occurrence of $F$. pseudograminearum and effect of climate (greater in 2008) also agree with the previous research, suggesting that the distribution and infection of Fusarium spp. involved in crown rot is highly variable and related to climate and cropping system (2$4,8,10,13,14,20,27,43,46,47)$. The general trends found in this study apply to other wheat-producing areas of the world.

Although FCR disease symptom development has been thought previously to be associated with warmer temperatures and lower annual precipitation, conditions also associated with drought stress, our results show that symptom development and species distribution is variable and related to climate. Prior to this study, species distribution throughout the wheat-growing regions was less evident. The distribution of $F$. culmorum in areas with higher precipitation and cooler temperatures and the widespread distribution of $F$. pseudograminearum agree with that of others around the world, especially in Australia $(2,3,6,8,10)$. The association of F. pseudograminearum with node score and greater FCR disease severity also agrees with research and general observations by others that it is a more aggressive species $(3,8,12,41,43)$.

This study resulted in the collection of nearly 1,000 isolates, of which 280 have been catalogued and stored for use in future studies. Knowledge gained from this study in terms of FCR occurrence, disease severity, and species distribution has implications for breeding and management that can be utilized by researchers, agronomists, and growers. Future research should focus on current levels of resistance in local PNW cultivars and on identification of novel germplasm resistant to Fusarium isolates identified in this study. From a pathological perspective, it would be beneficial to screen the isolates collected in this study on current cultivars to determine their pathogenicity and potential crop damage. We expect that the factor analysis data and factor scores from our sites will be useful in the future to determine the effects of climate on other root- and crown-rotting diseases of wheat and other crops that in the region.

\section{ACKNOWLEDGMENTS}

This research was funded by the Washington Grains Commission Project 7345 entitled "The development of wheat varieties resistant or tolerant to Fusarium crown rot". Additional funding was obtained from Washington Grains Commission projects 5345 and 6345, and USDA Agricultural Research Service (in-house) projects 5348-21220-003-00D and 5348-22000-013-00. We thank the Pacific Northwest wheat growers involved with this survey and the Washington Grains Commission.

\section{LITERATURE CITED}

1. Abatzoglou, J. T., 2011. Development of a gridded surface meteorological data for ecological applications and modelling. Int. J. Climatol. doi:10:1002/joc.3413

2. Backhouse, D., Abubakar, A. A., Burgess, L. W., Dennis, J. I., Hollaway, G. J., Wildermuth, G. B., Wallwork, H., and Henry, F. J. 2004. Survey of 
Fusarium species associated with crown rot of wheat and barley in eastern Australia. Australas. Plant Pathol. 33:255-261.

3. Backhouse, D., and Burgess, L. W. 2002. Climatic analysis of the distribution of Fusarium graminearum, F. pseudograminearum and $F$. culmorum on cereals in Australia. Australas. Plant Pathol. 31:321-327.

4. Backhouse, D., Burgess, L. W., and Summerell, B. A. 2001. Biogeography of Fusarium. Pages 122-137 in: Fusarium-Paul E. Nelson Memorial Symposium. B. E. Summerell, J. F. Leslie, D. Backhouse, W. L. Bryden, and L. W. Burgess, eds. The American Phytopathological Society Press, St. Paul, MN

5. Bentley, A. R., Cromey, M. G., Farrokhi-Nejad, R., Leslie, J. F., Summerell, B. A., and Burgess, L. W. 2006. Fusarium crown and root rot pathogens associated with wheat and grass stem bases on the South Island of New Zealand. Australas. Plant Pathol. 35:495-502.

6. Bentley, A. R., Milgroom, M. G., Leslie, J. F., Summerell, B. A., and Burgess, L. W. 2009. Spatial aggregation in Fusarium pseudograminearum populations from the Australian grain belt. Plant Pathol. 58:2332.

7. Bentley, A. R., Tunali, B., Nicol, J. M., Burgess, L. W., and Summerell, B. A. 2006. A survey of Fusarium species associated with wheat and grass stem bases in northern Turkey. Sydowia 58:163-177.

8. Burgess, L. W., Backhouse, D., Summerell, B. A., and Swan, L.J. 2001. Crown rot in wheat. Chapter 20 in: Fusarium-Paul E. Nelson Memorial Symposium. B. E. Summerell, J. F. Leslie, D. Backhouse, W. L. Bryden, and L. W. Burgess, eds. American Phytopathological Society Press, St. Paul, MN.

9. Burgess, L. W., Liddell, C. M., and Summerell, B. A. 1988. Laboratory Manual for Fusarium Research, 2nd ed. The University of Sydney, Sydney, Australia.

10. Burgess, L. W., Wearing, A. H., and Toussoun, T. A. 1975. Surveys of Fusaria associated with crown rot of wheat in eastern Australia. Aust. J. Agric. Res. 26:791-799.

11. Chakraborty, S., Liu, C. J., Mitter, V., Scott, J. B., Akinsanmi O. A., Ali, S., Dill-Macky, R., J. Nicol, Backhouse, D., and Simpfendorfer, S. 2006. Pathogen population structure and epidemiology are keys to wheat crown rot and Fusarium head blight management. Australas. Plant Pathol. 35:643-655.

12. Cook, R. J. 1968. Fusarium root and foot rot of cereals in the Pacific Northwest. Phytopathology 58:127-131.

13. Cook, R. J. 1981. Fusarium diseases of wheat and other small grains in North America. Chapter 4 in: Fusarium: Diseases, Biology and Taxonomy. P. E. Nelson, T. A. Toussoun, and R. J. Cook, eds. The Pennsylvania State University Press, University Park.

14. Cook, R. J., and Veseth, R. J. 1991. Wheat Health Management. American Phytopathological Society Press, St. Paul, MN.

15. Douglas, C. L., Rickman, R. W., Klepper, B. L., and Zuzel, J. F. 1992. Agronomic zones for dryland winter wheat producing areas of Idaho, Washington, and Oregon. Northwest Sci. 66:26-34.

16. Douglas, C. L., Wysocki, D. J., Zuzel, J. F., Rickman, R. W., and Klepper, B. L. 1990. Agronomic zones for the dryland Pacific Northwest. A Pacific Northwest Extension Publication. PNW No. 354:1-8.

17. Hill, J. P., Fernandez, J. A., McShane, and M. S. 1983. Fungi associated with common root rot of winter wheat in Colorado and Wyoming. Plant Dis. 67:795-797.

18. Hipple, K. W. 2011. Washington Soil Atlas. Washington NRCS. http://www.nrcs.usda.gov/wps/portal/nrcs/detail/wa/soil/?cid=nrcs144p2_ 036334

19. Inglis, D. A., and Cook, R. J. 1986. Persistence of chlamydospores of Fusarium culmorum in wheat fields of eastern Washington. Phytopathology 76:1205-1208.

20. Klein, T. A., Burgess, L. W., and Ellison, F. W. 1990. Survey of the incidence of whiteheads in wheat crops grown in northern New South Wales, 1976-1981. Aust. J. Exp. Agric. 30:621-627.

21. Lesley, J. F., Summerell, B. A., and Bullock, S. 2006. The Fusarium Laboratory Manual. Blackwell Publishers, Ames, IA.

22. Li, H. J., Arterburn, M., Jones, S. S., and Murray, T. D. 2004. A new source of resistance to Tapesia yallundae associated with a homoeologous group 4 chromosome in Thinopyrum ponticum. Phytopathology 94:932937.

23. Loehlin, J. C. 2004. Latent Variable Models. Lawrence Erlbaum Associates, Inc., Mahwah, NJ.

24. Matusinsky, P., Mikolasova, R., Klem, K., and Spitzer, T. 2009. Eyespot infection risks on wheat with respect to climatic conditions and soil management. J. Plant Pathol. 91:93-101.

25. Moya-Elizondo, E. A., Rew, L. J., Jacobsen, B. J., Hogg, A. C., and Dyer, A. T., 2010. Distribution and prevalence of Fusarium crown rot and common root rot pathogens of wheat in Montana. Plant Dis. 95:10991108 .
26. Nelson, P. E., Toussoun, T. A., and Cook, R. J. 1981. Fusarium: Diseases, Biology and Taxonomy. The Pennsylvania State University Press, University Park.

27. Nicol, J. M., Bolat, N., Bagci, A., Trethowan, R. T., William M., Hekimhan, H., Yildirim, A. F., Sahin, E., Elekccioğlu, H., Toktay, H., Tunali, B., Hede, A., Taner, S., Braun, H. J., Van Ginkel, M., Arisoy, Z., Yorgancilar, A., Tulek, A., Erdurmus, D., Buyuk, O., and Aydogdu, M. 2007. The international breeding strategy for the incorporation of resistance in bread wheat against the soil-borne pathogens (dryland root rot and cyst and lesion cereal nematodes) using conventional and molecular tools. Pages 125-137 in: Wheat Production in Stressed Environments. H. T. Buck, J. E. Nisi, and N. Salomon, eds. Springer, Dordrecht, The Netherlands.

28. Nirenberg, H. I. 1976. Untersuchungen über die morphologische und biologische Differenzierung in der Fusarium Sektion Liseola. Mitt. Biol. Bundesanst. Land Forstwirtsch. (Berlin-Dahlem) 169:1-117.

29. Papendick, R. I., and Cook, R. J. 1974. Plant water stress and development of Fusarium foot rot in wheat subjected to different cultural practices. Phytopathology 64:358-363.

30. Paulitz, T. C., Smiley, R. W., and Cook, R. J. 2002. Insights into the prevalence and management of soil-borne cereal pathogens under direct seeding in the Pacific Northwest, U.S.A. Can. J. Plant Pathol. 24:416-428.

31. Poole, G. J. 2010. Identification of quantitative trait loci (QTL) for resistance to Fusarium crown rot in wheat and a survey of Fusarium pseudograminearum and F. culmorum in the Pacific Northwest of the US. Ph.D. dissertation, Washington State University, Pullman.

32. Purss, G. S. 1970. Resistance to common root rot (Cochliobolus sativus) in wheat in Queensland. Aust. J. Exp. Agric. Anim. Husb. 10:497-501.

33. R Development Core Team. 2011. R: A language and environment for statistical computing. $\mathrm{R}$ Foundation for Statistical Computing. http://www.R-project.org/

34. Rehfeldt, G. E. 2006. A spline model of climate for the western United States. USDA-FS. Rocky Mountain Res. Stn. Gen. Tech. Rep. RMRSSTR-165.

35. Scardaci, S. C., and Webster, R. K. 1982. Common root rot of cereals in California. Plant Dis. 66:31-34.

36. Schilling, A. G., Moller, E. M., and Geiger, H. H. 1996. Polymerase chain reaction-based assays for species-specific detection of Fusarium culmorum, F. graminearum, and F. avenaceum. Phytopathology 86:515-522.

37. Schillinger, W. F., Papendick, R. I., and McCool, D. K. 2010. Soil and water challenges for Pacific Northwest agriculture. Pages 47-80 in: Soil and Water Conservation Advances in the United States. T. M. Zobeck and W. F. Schillinger, eds. Soil Sci. Soc. Am. Spec. Publ. 60. Madison, WI.

38. Schroeder, K. L., and Paulitz, T. C. 2006. Root diseases of wheat and barley during the transition from conventional tillage to direct seeding. Plant Dis. 90:1247-1253.

39. Sitton, J. W., and Cook, R. J. 1981. Comparative morphology and survival of chlamydospores of Fusarium roseum 'Culmorum' and 'Graminearum'. Phytopathology 71:85-90.

40. Smiley, R. W. 2009. Water and temperature parameters associated with winter wheat diseases caused by soilborne pathogens. Plant Dis. 93:7380 .

41. Smiley, R. W., Gourlie, J. A., Easley, S. A., Patterson, L.-M., and Whittaker, R. G. 2005. Crop damage estimates for crown rot of wheat and barley in the Pacific Northwest. Plant Dis. 89:595-604.

42. Smiley, R. W., Gourlie, J. A., Easley, S. A., Patterson, L.-M., and Whittaker, R. G. 2005. Pathogenicity of fungi associated with the wheat crown complex in Oregon and Washington. Plant Dis. 89:949-957.

43. Smiley, R. W., and Patterson, L. M. 1996. Pathogenic fungi associated with Fusarium foot rot of winter wheat in the semiarid Pacific Northwest USA. Plant Dis. 80:944-949.

44. Smiley, R. W., and Yan, H. 2009. Variability of Fusarium crown rot tolerances among cultivars of spring and winter wheat. Plant Dis. 93:954-961.

45. Specht, L. P., and Rush, C. M. 1988. Fungi associated with root and foot rot of winter wheat and populations of Cochliobolus sativus in the Texas Panhandle. Plant Dis. 72:959-963.

46. Strausbaugh, C. A., Bradley, C. A., Koehn, A. C., and Forster, R. L. 2004. Survey of root disease of wheat and barley in southeastern Idaho. Can. J. Plant Pathol. 26:167-176.

47. Steinkellner, S., and Langer, I., 2004. Impact of tillage on the incidence of Fusarium spp. in soil. Plant Soil 267:13-22.

48. Suhr, D. D. 2005. Principal component analysis vs. exploratory factor analysis. Paper 230-30 in: Proc. Thirtieth Annu. SAS Users Group Int. Conf. SAS Institute Inc., Cary, NC. http://www2.sas.com/proceedings/ sugi30/203-30.pdf

49. West, J. S., Holdgate, S., Townsend, J. A., Edwards, S. G. Jennings, P., and Fitt, B. D. L. 2012. Impacts of changing climate and agronomic factors on Fusarium ear blight of wheat in the UK. Fungal Ecol. 5:53-61. 